\title{
Methane Emission Control at the High- Productive Longwall Panels of the Yalevsky Coal Mine
}

\author{
Anatoly Meshkov ${ }^{1}$, Oleg Kazanin ${ }^{2}$, and Andrey Sidorenko ${ }^{3}$ \\ ${ }^{\prime}$ JSC SUEK Kuzbass, 652507, 1, Vasilyev St., Leninsk-Kuznetsky, Russia \\ ${ }^{2,3}$ Saint Petersburg Mining University, 2, 21 st Line, St Petersburg 199106, Russia
}

\begin{abstract}
The analysis of the experience of methane emission control at the V. D. Yalevsky mine (Kuznetsk coal basin, Russia) during the series of shallow gassy coal seams mining with the high productive longwall was performed. The analysis of the efficiency of gob degassing by the vertical wells and isolated methane removal by gas-suction fans is performed. The efficiency of reducing the distance between ventilation crosscuts between entries is shown. It is also shown that the problems of providing the longwall high productivity in conditions of increasing the natural gas content in the coal seams are associated with gas emission from the extracted coal seam and the lack of effective methods for its early and preliminary degassing. Recommendations for using advanced mining of close-up coal seams as an effective method of degassing of rock mass within the zone of influence of undermining and overmining are given.
\end{abstract}

\section{Introduction}

A necessary condition for ensuring the economic efficiency of underground mining of steam coals is a high productivity of mining operations. High productivity of underground coal mining is provided by the using of longwall mining system, which takes more than $90 \%$ of total underground coal mining production in Russia. Most of the being mined coal seams in Russia are gas-bearing and their intensive mining requires effective methane emission control including ventilation, degassing and isolated removal of the methane-air mixture. The use of reliable high-productive equipment at Russian coal mines has significantly increased the longwall productivity and provided record levels of productivity [1-5]. However, as the depth of mining operations increases, the natural gas content of coal seams gradually increases and the methods used for methane emission control are often not effective enough. In this connection, improving the efficiency of methane emission control techniques is an urgent task that determines the productivity and safety of underground coal mining. This paper includes the analysis of the experience of methane emission control during the longwall mining of the series of gas-bearing coal seams at the V. D. Yalevsky mine. In 2017-2018, several longwall productivity world records 1.4-1.56 million tons per month [1] were set at the V. D. Yalevsky mine during the coal seam 50 mining. The purpose of the research is to study the mining and geological factors that determine the effectiveness of methane emission control at high-productive coal panels and to develop 
recommendations for improving the efficiency of methane emission control techniques during intensive mining of gas-bearing coal seam series.

\section{Ventilation schemes and drainage techniques}

Two coal seams are being mined at the V. D. Yalevsky mine: seam 50 with a thickness of $3.7 \mathrm{~m}$ and seam 52 with a thickness of $4.3 \mathrm{~m}$. Coal seam 52 lies $90 \mathrm{~m}$ above seam 50 and is mined ahead of seam 50 (figure 1). When mining the seam 50 the length of the longwall is $400 \mathrm{~m}$. Longwall panels is developed by paired entries. A combined ventilation scheme (figure 2) was used to ventilate the gob, which provided for an isolated remove of the methane-air mixture through the rear crosscut. For the isolated removal of the methane-air mixture through the rear crosscut, degassing pipes were used, connected through vertical large diameter wells of $(600 \mathrm{~mm})$ to gas-suction fans installed on the ground surface. For effective degassing of the gob, degassing wells $(220 \mathrm{~mm}$ in diameter) were used, drilled from the earth's surface. Four degassing wells were in operation simultaneously. 2600$3600 \mathrm{~m}^{3} / \mathrm{min}$ of air were supplied for ventilation of the longwall panel, degassing wells were removed up to $250 \mathrm{~m}^{3} / \mathrm{min}$ of methane-air mixture, and the volume of isolated remove reached $700 \mathrm{~m}^{3} / \mathrm{min}$.

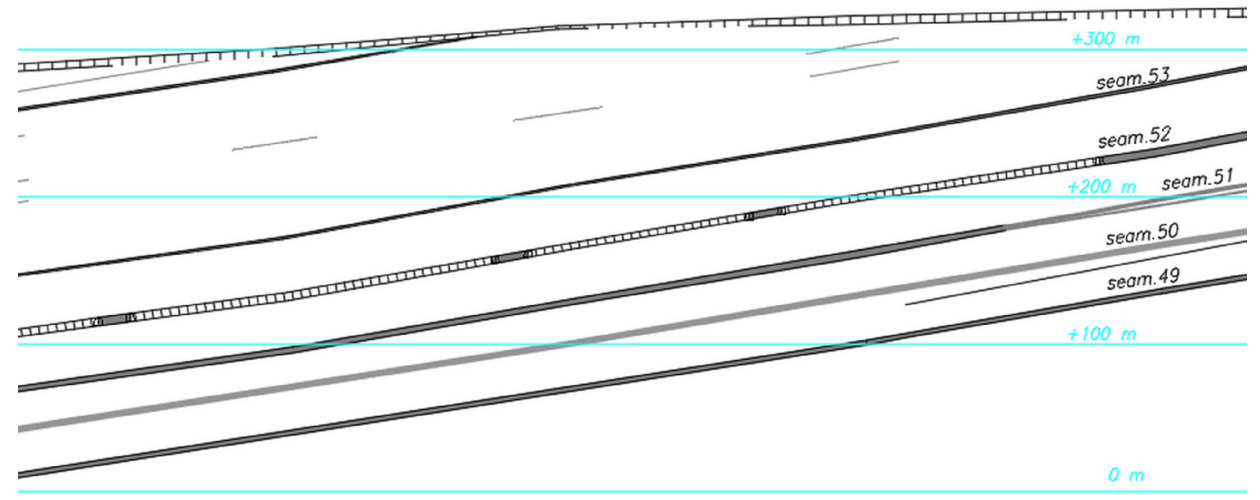

Fig. 1. Geological cross-section (V.D. Yalevsky mine).

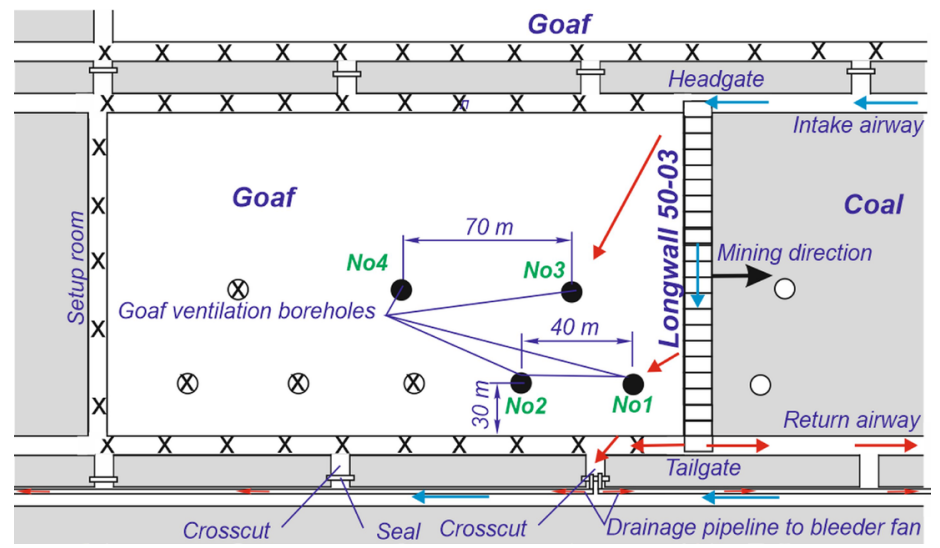

Fig. 2. Methane emission control at the coal seam 50 longwall panels: ventilation, degassing and isolated remove of methane-air mixture. 
During the research, data from the gas monitoring equipment (methane sensors, air flow sensors) and data of the longwall productivity were analyzed. Also, using the methods of existing regulatory documents, calculations of the values of methane emission from the under-mined and over-mined seams at different longwall productivity were made, taking into account various options for the order of mining the seams.

\section{Results and discussion}

The performed mine observations showed that the share of the gob during the mining of the 50-03 longwall panel accounts for about $90 \%$ of the volume of methane removed. In this case, degassing wells are removed up to $99 \mathrm{~m}^{3} / \mathrm{min}$ (figure 3). The isolated remove accounts for only $7-15 \%$ of the methane removed, but the main task of the isolated remove is to exclude the movement of air with a high concentration of methane from the gob into the coal face. The main volumes of methane from the gob are removed by degassing wells $\# 1$ and \#2 (figure 2), wells \# 3 and \# 4 are additional and the concentration of methane in them is $1.5-2$ times lower (20-30\%). Methane emission at the longwall panels changes by more than 2 times even under constant longwall productivity, which is associated with the periodic caving of the main roof and the growth of methane emission from the undermined coal seams [6-7]. It should be noted that the specified volumes of captive methane are not the limit for the methane emission control system used at the V. D. Yalevsky mine, since there is already experience in removing methane in volumes up to $230 \mathrm{~m}^{3} / \mathrm{min}$ during the coal seam 52 mining. During the seam 50 longwall panel mining methane emission from undermined strata in the gob is much less than when mining the seam 52 , because the primary mining of the overlying seam 52 is allowed to remove significant amounts of methane from the coal seams 52 and 53. A significant reserve of methane emission control capability excluded exceeding the permissible methane concentrations even at longwall 5003 productivity 60 thousand tons of coal per day. However, when the 50-03 longwall panel has been mined, the mining operations was carried out at depths of $220-250 \mathrm{~m}$ and the natural gas content of the coal seam did not exceed $5 \mathrm{~m}^{3} / \mathrm{t}$. The subsequent 50-04 and 50-05 longwall panels were mined at great depths $(250-430 \mathrm{~m})$ with an increase in the coal seam's methane content up to $12 \mathrm{~m}^{3} / \mathrm{min}$. The increase in the methane content of the coal seam led to the need to limit the longwall productivity, which was reduced from 700-1620 thousand tons per month in 2018 (longwall panel 50-04) to 600-730 thousand tons per month in 2019 (longwall panel 50-05). Thus, at present, the main factor limiting the longwall productivity is the high methane emission from the coal seam 50. It should be noted that the use of advance and preliminary degassing of the mined coal seam 50, as shown by the experience of its use in the mining of the coal seam 52, is low effective, and the costs of such degassing are very high [8-10]. In addition, with increasing depth, the cost of degassing the mined coal seam increases, and its efficiency decreases [11-14]. 


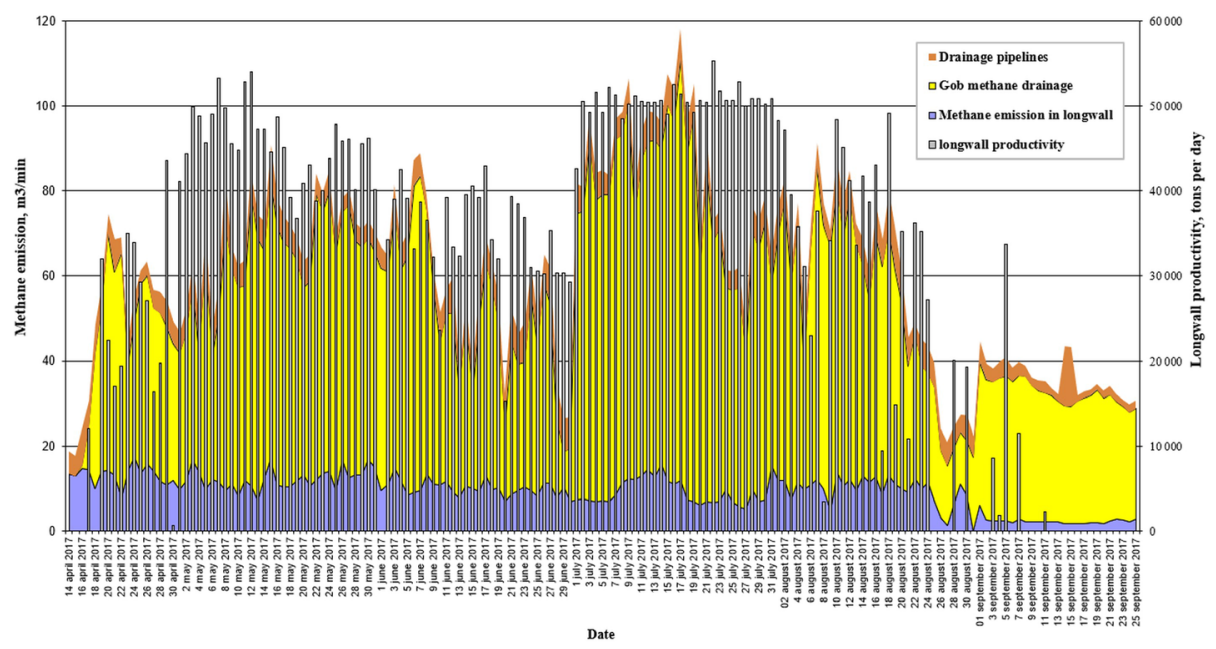

Fig. 3. Longwall productivity and methane emission at longwall panel.

According to our opinion, the most effective way to control methane emission, which allows you to avoid limiting the longwall productivity, is to use the effect of undermining or overmining. At the same time, the greatest effect is achieved as a result of undermining. In this regard, we recommend changing the sequence of coal mining for the V. D. Yalevsky mine. At present, the coal seam 50 which lies $80-90 \mathrm{~m}$ below seam 52, is mining after the mining of seam 52 (figure 1). Thus, the primary coal seam 52 mining leads to the degassing of the undermined seams, but the influence on the coal seams 51 and 50 lying below is much less. As a rational sequence of coal seam series mining, it is recommended to mine seam 51 after seam 52, which is not currently being worked out, since it is observed to be stratified into two seams (at a depth of up to $150 \mathrm{~m}$ ), and also because of the danger of the influence of stress shadow zones formed by the pillars left on the coal seam 52 . However, the mining of coal seam 51 can be carried out below the stratification site, since it is aimed at solving the problem of degassing coal seam 50 in deeper areas. Exclusion of the influence of stress shadow zones can be provided by the location of the panel entries outside these zones. Thus, the mining of the coal seam 51 before the start of work on the areas of the coal seam 50 that have an increased gas content will allow for partial degassing of the coal seam 50 due to the close location of the coal seams. By unloading the seam 50 from the stresses and increasing the permeability of inter-seams rocks, methane will flow into the gob area of the coal seam 51, from where it can be removed through vertical degassing wells. It should be noted that subsequent mining of the coal seam 50 will be characterized not only by a reduction of the methane emission from the mined seam, but also a significant reduction of methane emission from undermined strata by the repeated undermining of strata previously overmined by seam 52 and mined seam 51 . Thus, the use of the recommended sequence of coal seam series mining allows to increase the efficiency of methane emission control and the longwall productivity at the coal seam 50 .

To quantify the effect of changing the sequence of the coal seam series mining, the expected gas emission from the under-mined and over-mined coal seams was calculated at different longwall productivity under the applied and recommended sequence of coal seam series mining (Table 1). 
Table 1. Calculated methane emission at mined longwall panels of the coal seam 50.

\begin{tabular}{|c|c|c|c|c|}
\hline \multirow{2}{*}{$\begin{array}{c}\text { Sequence of coal } \\
\text { seam mining }\end{array}$} & $\begin{array}{c}\text { Average } \\
\text { longwall } \\
\text { productivity, } \\
\text { t/day }\end{array}$ & \multicolumn{3}{|c|}{ Methane emission, m3/min } \\
\cline { 3 - 5 } & & $\begin{array}{c}\text { Into the } \\
\text { longwall } \\
\text { face }\end{array}$ & Into the gob & Total \\
\hline $\begin{array}{c}\text { Used (at first - the coal } \\
\text { seam 52, second - the coal } \\
50 \text { ) }\end{array}$ & 35000 & 19.69 & 132.95 & 152.64 \\
\cline { 2 - 5 } & 50000 & 28.13 & 189.93 & 218.06 \\
\hline $\begin{array}{c}\text { Recommended (at first - } \\
\text { the coal seam 52, second } \\
\text { the coal seam 51 (one } \\
\text { longwall panel), third - } \\
\text { the coal seam 50) }\end{array}$ & 35000 & 15.95 & 118.33 & 134.27 \\
\cline { 3 - 5 } & 50000 & 22.79 & 169.04 & 191.82 \\
\hline
\end{tabular}

The results of the calculations performed (table 1) showed that it is possible to eliminate the coal seam 50 longwall productivity restriction. Now coal seam 50 longwall productivity reaches 50,000 tons per day when applying the recommended sequence of coal seam series mining, by reducing the methane emission of the longwall face and the gob. Since currently the average coal seam 50 longwall productivity is about 35,000 tons per day, the proposed sequence of coal seam series mining will not require additional costs and will increase the longwall productivity by 1.5 times, which will significantly increase the efficiency of coal mining at the mine.

\section{Conclusions}

Methane emission control methods used in the mines of the Kuznetsk coal basin ensure the removal of up to $250 \mathrm{~m}^{3} / \mathrm{min}$ of methane from the longwall panels. The main volume of methane (up to $200 \mathrm{~m}^{3} / \mathrm{min}$ ) can be removed from the gob, where it comes from the undermined and over-mined coal seams, through vertical degassing wells drilled from the earth's surface and connected to vacuum pumping units. For effective methane emission control, it is necessary to use an isolated remove, the task of which is to prevent the flow of methane from the gob to the longwall face area. The use of the described method of methane emission control (figure 2), as shown by experience, allows to reach the longwall productivity up to 60,000 tons per day. However, as the depth of work increases and the methane content of the mined seam increases, the possibilities for effective methane emission control are completed. The main limitations of the longwall productivity are associated with high methane emission from the coal seam being mined.

The performed studies have shown that it is possible to eliminate the limitations of the longwall productivity in the conditions of the V. D. Yalevsky mine by changing the sequence of coal set series mining. Taking into account the actual situation, when several longwall panels at the coal seam 50 have already been mined, it may be recommended to mine longwall panels at coal seam 51 in order to eliminate longwall productivity restrictions during further development of mining the coal seam 50 longwall panels in conditions of increased gas content. It should be noted that the possibility of ensuring coal seam degassing by advancing the mining of close-lying coal seams (longwall panels) with the removal of gob methane is confirmed by the experience of coal seam mining in the conditions of the Vorkuta coal deposit of the Pechora coal basin.

It should be noted that sequential mining of coal seams in a descending order to ensure degassing of the underlying seams in the conditions of the Kuznetsk coal basin is only appropriate if the distance between the close-lying seams is less than $35 \mathrm{~m}$. Priority mining 
of coal seams with the removal of methane from the gob can be recommended for partial or complete eliminating of restrictions to ensure high-intensity mining of gas-bearing coal seams. Thus, sequential mining of the coal seams during the mining of the gas-bearing coal seam series can provide effective degassing of each subsequent seam even in descending order of coal seam mining, provided that the distance between the coal seams does not exceed $35 \mathrm{~m}$ (the less distance the higher the efficiency of degassing). Exceeding the specified value $(35 \mathrm{~m})$ leads to a sharp decrease in the efficiency of degassing and a decrease in the area of influence of overmining.

As an additional measure to improve the efficiency of methane emission control, it is recommended that the distance between ventilation crosscuts at the long wall panel be reduced down to $100 \mathrm{~m}$ or less in order to reduce the volume of methane removed by gassuction fans and thus creates additional opportunities for removing methane from the longwall face.

\section{References}

1. A.A. Meshkov, M.A. Volkov, A.A. Ordin, A.M. Tymoshenko, D.V. Botvenko, Coal, 7 (2018)

2. V. Artemyev and P. McInally, Coal operators conference (SpBMU, Saint Peternurg, 2018)

3. E.P. Yutyaev, Coal, 5 (2017)

4. A.V. Stebnev, D.A. Zadkov, V.V. Gabov, S.G. Mukhortikov, Eurasian mining, 2, 28 (2017)

5. S.S. Peng, Longwall mining (Springer, New York, 2019)

6. A.A. Sidorenko, V.V. Ivanov, S.A. Sidorenko, Journal of physics: conference series, 1333:3 032079

7. A.M. Cherdantsev, International Journal of Civil Engineering and Technology (IJCIET), 9, 13 (2018).

8. S.V. Gantry, V.F. Zamyshlyaev, V.Yu. Linnik, Mining information and analytical bulletin, OB1 (2013)

9. Y.V. Ilyushin, O.V. Afanaseva, Journal of mining institute, 240 (2019)

10. Y. Ilyushin, A. Mokeev, ARPN Journal of Engineering and Applied Sciences, 14(6) (2019)

11. Y. Zhukovskiy, N. Koteleva, IOP Conference Series: Materials Science and Engineering, 124:1 (2016)

12. Y. Zhukovskiy, N. Koteleva, IOP Conference Series: Materials Science and Engineering, 177:1 (2017)

13. Y. Lu, S. Shi, Q. Ye, Z. Tian, Journal of Residuals Science \& Technology, 14:3, 373 (2017)

14. C. Zhang, S. Tu, L. Zhang, Q. Bai, Y. Yuan, F. Wang, Journal of Geophysics and Engineering, 13:2, 181 (2016) 